\title{
Evaluation and management of esophageal manifestations in systemic sclerosis
}

\author{
Konstantinos Denaxas, Spyros D. Ladas, George P. Karamanolis \\ National and Kapodistrian University of Athens, "Laikon” General Hospital, Athens, Greece
}

\begin{abstract}
Systemic sclerosis (SSc) is a multisystemic autoimmune connective tissue disorder; in the gastrointestinal tract, the esophagus is the most commonly affected organ. Symptoms of esophageal disease are due to gastroesophageal reflux disease (GERD) and esophageal motor dysfunction. Since the development of high-resolution manometry (HRM), this method has been preferred for the study of SSc patients with esophageal involvement. Using HRM, classic scleroderma esophagus, defined as absent or ineffective peristalsis of the distal esophagus in combination with a hypotensive lower esophageal sphincter, was found in as many as 55\% of SSc patients. Endoscopy is the appropriate test for evaluating dysphagia and identifying evidence and possible complications of GERD. In the therapeutic area, treatment ranges from general supportive measures to the administration of drugs such as proton pump inhibitors and/or prokinetics. However, as many SSc patients do not respond to existing therapies, there is an urgent need for new therapeutic modalities. Buspirone, a 5-hydroxytryptamine $1 \mathrm{~A}$ receptor agonist, could be a putative therapeutic option, as it was found to exert a significant beneficial effect in SSc patients with esophageal involvement. This review summarizes our knowledge concerning the evaluation and management of esophageal manifestations in SSc patients, including emerging therapeutic modalities.
\end{abstract}

Keywords Systemic sclerosis, scleroderma esophagus, high-resolution manometry, 5-HT1A receptor agonist, buspirone

Ann Gastroenterol 2018; 31 (1): 1-6

\section{Introduction}

Systemic sclerosis (SSc), a connective tissue disease of unknown origin, occurs most frequently in females aged 40-65 years (female:male ratio 8:2). Gastrointestinal tract involvement is very common and the esophagus is the most frequently affected part (up to $90 \%$ of patients) [1-4]. The pathogenesis of esophageal involvement in SSc is multifactorial. On the basis of clinical, immunological, and histopathological observations, three pathways have been proposed as being involved in scleroderma: vascular alterations, an abnormal immune response, and disturbances in the regulation of connective tissue metabolism. The pathogenesis of SSc is initiated

Academic Department of Gastroenterology, National and Kapodistrian University of Athens, "Laikon" General Hospital, Athens, Greece

Conflict of Interest: None

Correspondence to: Dr Konstantinos Denaxas, Academic Department of Gastroenterology, "Laikon" General Hospital, Agiou

Thoma 17, 11527 Athens, Greece, e-mail: kdenaxas1@yahoo.gr

Received 18 May 2017; accepted 28 October 2018;

published online 18 January 2018

DOI: https://doi.org/10.20524/aog.2018.0228 with vascular endothelial activation (vasculopathy), reflected in recurrent episodes of reperfusion and vasoconstriction, and this progresses to episodic and sustained tissue ischemia with inappropriate immunological and reparative changes. Excessive deposition of collagen and collagen matrix from activated profibrogenic fibroblasts ensues, resulting in fibrosis and replacement of tissue in the skin and multiple internal organs, including the esophagus [5-11].

\section{Symptoms and complications of esophageal dysfunction in SSC}

Patients with SSc and esophageal involvement usually report two types of symptoms: due to gastroesophageal reflux disease (GERD), such as heartburn and regurgitation, and/ or due to esophageal dysmotility, such as dysphagia and chest pain $[5,12]$. Dysphagia may not only represent a symptom of dysmotility, but could also be the result of Candida esophagitis or of peptic stricture formation due to complicated GERD [13]. Overall, the incidence of esophageal symptoms in SSc has been estimated at between $40 \%$ and $80 \%$, even though a percentage of patients are totally asymptomatic despite their documented esophageal disease [5,12-16]. 
Complications of GERD, such as peptic strictures occur in up to $30 \%$ of patients [3,13,17-19], whereas Barrett's esophagus has been found in up to $37 \%[13,18-20]$. Moreover, GERD may contribute to interstitial lung disease via recurrent microaspiration of acid causing bronchoconstriction [21]. Although SSc patients have a risk of developing esophageal carcinoma, the use of proton pump inhibitors (PPIs) has decreased its incidence [22].

\section{Diagnosis}

Esophageal involvement can be assessed by the following methods:

\section{Manometry}

Classic manometry was, until recently, the gold standard method for the detection and assessment of esophageal dysmotility, especially in the early stages of esophageal involvement in SSc patients. The typical manometric findings include decreased lower esophageal sphincter (LES) pressure and absent or ineffective peristalsis of the distal esophagus $[12,19]$. The combination of distal aperistalsis and a hypotensive LES is called classic scleroderma esophagus. Since the development of high-resolution manometry (HRM), this method has been preferred for the study of SSc patients [23]. HRM, using multiple closely spaced pressure sensors, allows a better assessment of the whole esophagus and especially of the LES.

With HRM, the overall frequency of manometric abnormalities reported in SSc patients has been very high, affecting up to $75-80 \%$ of them. Hypotensive LES was encountered in more than $50 \%$ of patients, whereas esophageal body dysmotility was present in more than $60 \%$ of patients. Classic scleroderma esophagus was found in as many as $55 \%$ of patients [24-30]. In a well-characterized cohort of patients with SSc, we observed, using recent criteria for esophageal motility diagnosis [31], that classic scleroderma esophagus was the most prevalent contractility pattern in SSc patients [32]. Table 1 summarizes studies demonstrating the importance of HRM.

\section{pH monitoring}

Esophageal $\mathrm{pH}$ monitoring, with or without impedance, is considered the gold standard for gastroesophageal reflux detection. However, its role in the management of SSc patients is limited and in clinical practice it is only used in patients with resistant reflux symptoms. Thus, only few studies assess $\mathrm{pH}$ parameters in patients with SSc. Abnormal $\mathrm{pH}$ monitoring has been seen in up to $85 \%$ of patients [33-35]. Although the number of reflux events is similar between SSc patients and non-scleroderma patients, a small but well-designed study [36] found that SSc patients showed a greater number of events with longer duration. A recent retrospective study suggested a role of $\mathrm{pH}$ monitoring as a prognostic factor in patients with SSc and interstitial lung disease [37]. Esophageal pH monitoring was performed in $10 \mathrm{SSc}$ patients referred for lung transplantation and severe reflux, calculated via a self-administered score of $\mathrm{pH}$ monitoring. The authors found that the presence of abnormal $\mathrm{pH}$ was a better predictor of survival than abnormal pulmonary function tests. Thus, esophageal $\mathrm{pH}$ monitoring should be considered early in SSc patients with early-stage lung disease, as this test could identify those in whom intense antireflux therapy should be introduced to prevent GERD and its detrimental effects in patients awaiting lung transplantation.

\section{Endoscopy}

Upper endoscopy is the appropriate test for evaluating dysphagia, identifying evidence of GERD, such as esophagitis, and identifying possible reflux complications, such as esophageal stenosis, Barrett's esophagus and esophageal adenocarcinoma. Esophageal manifestations are more common in SSc patients than in the general population; thus, endoscopy should be performed in patients with SSc, even if they do not report reflux symptoms, as it is well known that symptoms are not predictive for the presence of esophagitis [18]. Prevalence of endoscopic esophagitis has been reported in up to $65 \%[13,14,18,33]$, whereas Barrett's esophagus was found in up to $7 \%$ of SSc patients [38]. A recent, prospective study that included fifty SSc patients with Barrett's esophagus (40 without and 10 with dysplasia) showed an overall $0.7 \%$ year rate of progression to adenocarcinoma, not greater than that seen in the general population [39].

\section{Treatment}

In general, the treatment is supportive and patients are advised to chew food well, avoid big bites, and use water as complimentary to solid foods. Moreover, in symptomatic SSc patients with esophageal involvement drug administration targeting either GERD symptoms or dysmotility symptoms could be offered.

\section{GERD therapies}

PPIs are considered as the standard of care for the treatment of GERD in SSc patients. However, the effective dose of PPIs for alleviating reflux symptoms in SSc patients is still under investigation. Few studies using standard doses of PPIs reported symptomatic improvement and healing of esophagitis [40-42]. Even though PPIs demonstrated a clear short-term benefit, the long-term efficacy of these drugs was not sustained and there was no evidence that progression of esophageal dysfunction was prevented [41]. We have to keep in mind that an estimated $40 \%$ of SSc patients 
Table 1 Studies that evaluated the important role of high-resolution manometry (HRM) in systemic sclerosis (SSc) disease

\begin{tabular}{|c|c|}
\hline Author & Aim of the study - methods - main conclusions \\
\hline Crowell et al [29] & $\begin{array}{l}\text { - To assess associations between SSc severity, health-related quality of life (HRQOL) and HRM findings in a } \\
\text { prospective study of } 200 \mathrm{SSc} \text { patients and } 102 \text { non-SSc (controls) } \\
\text { - HRM findings, symptoms, and HRQOL data were compared among diffuse SSc, limited SSc, and control } \\
\text { subjects } \\
\text { - Main results of this study: i) severe dysmotility is more common in SSc patients than in controls; ii) SSc } \\
\text { esophagus is found in only one-third of SSc patients; and iii) esophageal dysmotility reduces HRQOL in } \\
\text { patients with SSc }\end{array}$ \\
\hline Kimmel et al [28] & $\begin{array}{l}\text { - To evaluate the associations between SSc-related systemic manifestations and esophageal dys?motility } \\
\text { diagnoses (diagnosis?) using HRM in } 79 \text { SSc patients } \\
\text { - Main conclusion: more severe skin disease and worse pulmonary function were associated with absent } \\
\text { esophageal contractility }\end{array}$ \\
\hline Raja et al [35] & $\begin{array}{l}\text { - To evaluate the associations between objectively measured gastroesophageal involvement using HRM, } \\
24 \text {-h impedance-pH study, and clinical presentations in } 31 \text { SSc patients } \\
\text { - Main conclusions: i) presence and severity of gastroesophageal symptoms may not accurately reflect the } \\
\text { seriousness of esophageal involvement; ii) GERD severity is associated with presence of restrictive lung } \\
\text { pattern and pulmonary fibrosis; and iii) HRM and } 24 \text {-h pH-study should be considered more frequently } \\
\text { in the assessment of SSc patients }\end{array}$ \\
\hline Karamanolis et al [32] & $\begin{array}{l}\text { - To assess associations between scleroderma and non-scleroderma esophagus, diagnosed by HRM, and } \\
\text { other manifestations of disease (demographic characteristics, patient-reported symptoms, SSc subtypes, } \\
\text { pulmonary fibrosis, cutaneous ulcers, and anti-Scl-70 positivity) in } 54 \text { SSc patients } \\
\text { - To make comparisons between scleroderma and non-scleroderma esophagus with computed } \\
\text { tomography (CT) findings of esophageal lumen in } 26 \text { SSc patients with available data } \\
\text { - Main conclusions: i) scleroderma esophagus diagnosed by HRM was present in less than } 2 / 3 \text { of } \\
\text { symptomatic patients with SSc and associated only with esophageal dilation in CT; and ii) esophageal } \\
\text { dilation on chest CT may be a noninvasive alternative for evaluation of SSc patients with esophageal } \\
\text { symptoms }\end{array}$ \\
\hline Tang et al [30] & $\begin{array}{l}\text { - To evaluate the impact of cutaneous findings, Raynaud's phenomenon (RP) and pulmonary fibrosis (PF) } \\
\text { on demographics, symptoms, and esophageal motility in } 28 \text { SSc patients who underwent HRM in a 6-year } \\
\text { study } \\
\text { - Main results: i) heartburn and dysphagia are important symptoms that may be associated with disease } \\
\text { progression based on skin changes in SSc; ii) RP was associated with greater esophageal dysmotility; and } \\
\text { iii) coughing and wheezing were more severe in patients with PF }\end{array}$ \\
\hline Roman et al [24] & $\begin{array}{l}\text { - To more fully characterize esophageal motility disorders in } 51 \mathrm{SSc} \text { patients using HRM and to determine } \\
\text { predictive factors of esophageal involvement by making associations with other manifestations of } \\
\text { the disease (dermographic data, esophageal symptoms, presence of other organ involvement and } \\
\text { autoantibody profile, such as anti-Scl-70 antibodies, anticentromere antibodies [ACA]) } \\
\text { - Main conclusion: diffuse skin involvement, positive Scl-70 and negative ACA may predict esophageal } \\
\text { body dysmotility }\end{array}$ \\
\hline
\end{tabular}

showed no response to a standard PPI dose. Thus, a two- to fourfold increase in the daily dose of PPIs, in order to gain better symptom control in patients with a partial response, is common practice [43]. A recent study, involving $148 \mathrm{SSc}$ GERD patients, some of whom showed partial response to PPIs, compared the efficacy of a combination of omeprazole with domperidone, or with alginic acid, in alleviating reflux symptoms. The authors concluded that the addition of domperidone or alginic acid to omeprazole therapy was effective in the majority of non-responsive patients [44]. However, even with this approach, approximately $20 \%$ of patients did not respond. This study highlights the necessity for more potent anti-reflux drugs in order to reduce the severity and frequency of reflux symptoms in SSc patients. Endoscopic procedures, such as dilation with balloon dilators, have been proposed for use in patients with peptic strictures related to GERD [43].

\section{Motility therapies}

According to the pathophysiology of SSc, motility abnormalities could be among the mechanisms underlying GERD pathogenesis. Thus, various prokinetic drugs have been used in the treatment of SSc patients with esophageal involvement, such as metoclopramide, erythromycin, and cisapride [45-47]. It has been reported that metoclopramide and erythromycin may increase LES pressure in SSc patients [48-50], while cisapride has been shown to increase LES pressure and the amplitude of distal esophageal body peristalsis $[45,51]$. Based on these results, prokinetics are used in clinical practice. However, experience with the use of prokinetic drugs in SSc patients is bibliographically limited and has had controversial results. Moreover, their use is restricted because of safety profile issues (central nervous system, cardiovascular side effects). 
Domperidone, a peripheral dopamine antagonist, is currently the most common prokinetic agent used in clinical practice in patients with SSc, although data regarding its effect on esophageal motility are conflicting [46,47]. A recent study, involving $10 \mathrm{SSc}$ patients who underwent HRM before and after administration of $10 \mathrm{mg}$ domperidone, challenged the drug's effect on motility. Acute administration of domperidone had no effect upon any manometric parameters compared to the baseline values [52]. Moreover, there is some concern over safety issues, as domperidone has been associated with cases of sudden death due to its cardiac side effects $[53,54]$.

\section{Emerging therapies}

Buspirone, an orally available 5-hydroxytryptamine 1A (5-HT1A) receptor agonist, has shown a beneficial effect on esophageal motor function in healthy subjects. Thus, we studied the differences in HRM parameters in 20 SSc patients with esophageal involvement before and after acute administration of $10 \mathrm{mg}$ buspirone. We observed a significant increase in the LES resting pressure in up to $80 \%$ of SSc patients, from $9.4 \pm 2.6$ to $11.5 \pm 3.3 \mathrm{mmHg}(\mathrm{P}=0.0002)$. Moreover, a non-significant trend $(\mathrm{P}=0.09)$ toward an increased amplitude of esophageal body motility was also observed [52].

Based on this result, buspirone was administered in a 4-week open-label study that included SSc patients with symptomatic esophageal involvement despite PPI administration [55]. Twenty-two consecutive SSc patients underwent HRM before and after a 4-week administration of $20 \mathrm{mg}$ of buspirone, so that the efficacy of long-term buspirone administration on esophageal motor dysfunction and on esophageal symptoms could be evaluated. Following buspirone administration for 4 weeks, an increase in the LES resting pressure was observed in $15(68 \%)$ patients, with an enhancement from $7.7 \pm 3.9$ to $12.2 \pm 4.6 \mathrm{mmHg}(\mathrm{P}<0.00005)$. In an attempt to identify prognostic factors for the beneficial effect of buspirone, a moderate, but significant, inverse correlation between the increase in LES resting pressure and supra-aortic diameter, measured by chest computed tomography $(r=-0.589, \mathrm{P}=0.017)$ was found. Moreover, the severity of heartburn and regurgitation significantly decreased at 4 weeks compared with baseline $(\mathrm{P}=0.001$, and $\mathrm{P}=0.022$, respectively), whereas no significant improvement was found in the severity scores of chest pain and dysphagia. Concerning the safety issues, buspirone was well tolerated by all patients who completed the study and only self-limited adverse effects that did not affect their daily activities were observed.

\section{Surgical management}

Anti-reflux procedures, such as Nissen fundoplication, are generally considered suboptimal in SSc patients with reflux symptoms, because of the profound esophageal dysmotility seen in this disease. Indeed, $38-71 \%$ of patients who underwent fundoplication developed postoperative dysphagia, even though an improvement in the severity of reflux symptoms and in esophageal acid exposure has been reported after surgical intervention [56-58]. In an attempt to identify a better surgical option for the management of SSc-associated gastroesophageal reflux, a recent review of different surgical series proposed Roux-en-Y gastric bypass as an alternative. The authors showed that patients undergoing Roux-en-Y gastric bypass reported better postoperative GERD-related quality of life and less dysphagia compared with those undergoing fundoplication [59]. However, we have to keep in mind that Roux-en-Y should also be pursued with caution, because of the small intestinal dysmotility in SSc patients and the possibility of bacterial overgrowth.

Fig. 1 demonstrates an algorithm for the therapeutic management of SSc.

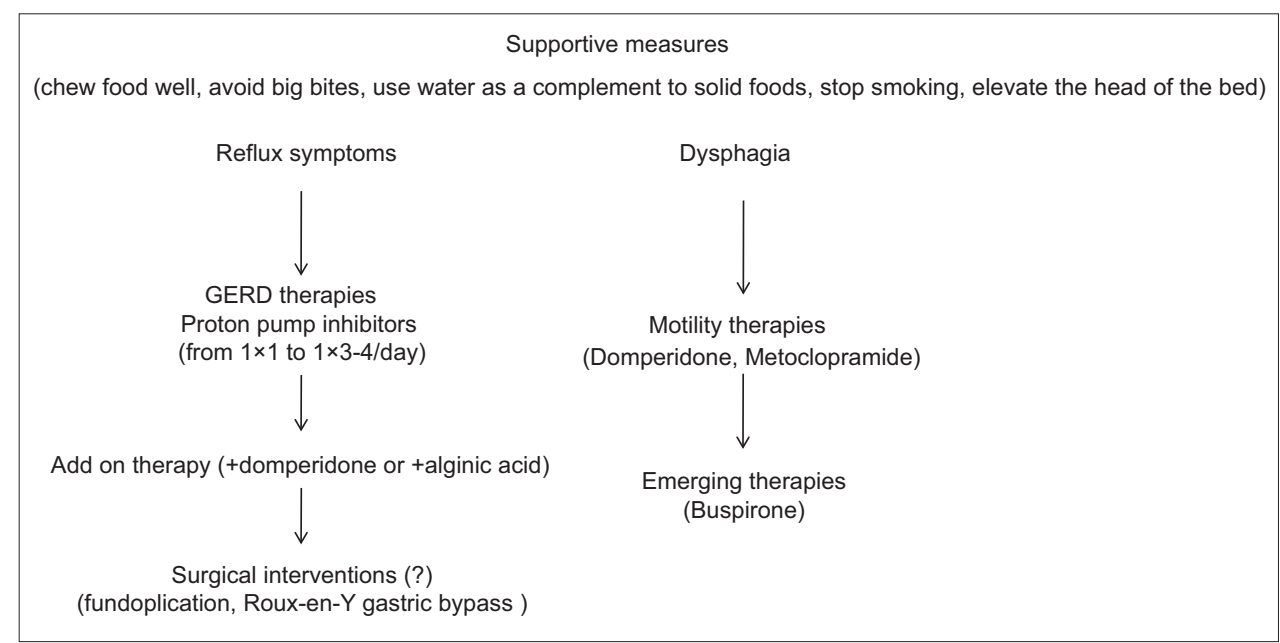

Figure 1 Algorithm for therapeutic approach to SSc patients with esophageal manifestations $S S c$, systemic sclerosis; GERD, gastroesophageal reflux disease 


\section{Concluding remarks}

Esophageal involvement in SSc is common, occurring in up to $90 \%$ of patients. It carries significant morbidity and mortality, which can be improved by its early diagnosis and treatment. Nowadays, HRM is the gold standard method used to identify SSc patients with esophageal motility disorders. Treatment for SSc-induced esophageal impairment, which includes PPIs, prokinetics and endoscopic interventions, is still a challenging process. Buspirone, a 5-HT1A receptor agonist, was found to exert a significant beneficial effect on both manometric and clinical parameters in the treatment of SSc patients with esophageal involvement, creating new data relating to future therapeutic modalities in that category of patients.

\section{References}

1. Varga J, Abraham D. Systemic sclerosis: a prototypic multisystem fibrotic disorder. J Clin Invest 2007;117:557-567.

2. Villadsen GE, Storkholm J, Zachariae H, Hendel L, Bendtsen F, Gregersen H. Oesophageal pressure-cross-sectional area distributions and secondary peristalsis in relation to subclassification of systemic sclerosis. Neurogastroenterol Motil 2001;13:199-210.

3. Clements PJ, Becvar R, Drosos AA, Ghattas L, Gabrielli A. Assessment of gastrointestinal involvement. Clin Exp Rheumatol 2003;21:S15-S18.

4. Kirby DF, Chatterjee S. Evaluation and management of gastrointestinal manifestations in scleroderma. Curr Opin Rheumatol 2014;26:621-629.

5. Ebert EC. Esophageal disease in scleroderma. J Clin Gastroenterol 2006;40:769-775.

6. Treacy WL, Baggenstoss AH, Slocumb CH, Code CF. Scleroderma of the esophagus. A correlation of histologic and physiologic finding. Ann Int Med 1963;59:351-356.

7. Cohen S. The gastrointestinal manifestations of scleroderma: pathogenesis and management. Gastroenterology 1980;79:155-166.

8. Attar A. [Digestive manifestations in systemic sclerosis]. Ann Med Interne (Paris) 2002;153:260-264.

9. Roberts CG, Hummers LK, Ravich WJ, Wigley FM, Hutchins GM. A case-control study of the pathology of oesophageal disease in systemic sclerosis (scleroderma). Gut 2006;55:1697-1703.

10. Gilliam AC. Scleroderma. Curr Dir Autoimmun 2008;10:258-279.

11. Gabrielli A, Avvedimento EV, Krieg T. Scleroderma. N Engl J Med 2009;360:1989-2003.

12. Ntoumazios SK, Voulgari PV, Potsis K, Koutis E, Tsifetaki N, Assimakopoulos DA. Esophageal involvement in scleroderma: gastroesophageal reflux, the common problem. Semin Arthritis Rheum 2006;36:173-181.

13. Abu-Shakra M, Guillemin F, Lee P. Gastrointestinal manifestations of systemic sclerosis. Semin Arthritis Rheum 1994;24:29-39.

14. Ling TC, Johnston BT. Esophageal investigations in connective tissue disease: which tests are most appropriate? J Clin Gastroenterol 2001;32:33-36.

15. Kaye SA, Siraj QH, Agnew J, Hilson A, Black CM. Detection of early asymptomatic esophageal dysfunction in systemic sclerosis using a new scintigraphic grading method. J Rheumatol 1996;23:297-301.

16. Harper RA, Jackson DC. Progressive systemic sclerosis. Br J Radiol 1965;38:825-834.

17. Orringer MB, Dabich L, Zarafonetis CJ, Sloan H. Gastroesophageal reflux in esophageal scleroderma: diagnosis and implications. Ann Thorac Surg 1976;22:120-130.

18. Zamost BJ, Hirschberg J, Ippoliti AF, Furst DE, Clements PJ, Weinstein WM. Esophagitis in scleroderma. Prevalence and risk factors. Gastroenterology 1987;92:421-428.

19. Weston S, Thumshirn M, Wiste J, Camilleri M. Clinical and upper gastrointestinal motility features in systemic sclerosis and related disorders. Am J Gastroenterol 1998;93:1085-1089.

20. Katzka DA, Reynolds JC, Saul SH, et al. Barrett's metaplasia and adenocarcinoma of the esophagus in scleroderma. Am J Med 1987;82:46-52.

21. Savarino E, Furnari M, de Bortoli N, et al. Gastrointestinal involvement in systemic sclerosis. Presse Med 2014;43:e279-e291.

22. Segel MC, Campbell WL, Medsger TA, Roumm AD. Systemic sclerosis (scleroderma) and esophageal adenocarcinoma: is increased patient screening necessary? Gastroenterology 1985;89:485-488.

23. Fox MR, Bredenoord AJ. Oesophageal high-resolution manometry: moving from research into clinical practice. Gut 2008;57:405-423.

24. Roman S, Hot A, Fabien N, et al; Réseau Sclérodermie des Hospices Civils de Lyon. Esophageal dysmotility associated with systemic sclerosis: a high-resolution manometry study. Dis Esophagus 2011;24:299-304.

25. Savariono E, Mei F, Parodi A, et al. Gastrointestinal motility disorder assessment in systemic sclerosis. Rheumatology (Oxford) 2013;52:1095-1100.

26. Calderaro DC, de Carvalho MA, Moretzsohn LD. Esophageal manometry in 28 systemic sclerosis Brazilian patients: findings and correlations. Dis Esophagus 2009;22:700-704.

27. Lahcene M, Oumnia N, Matougui N, Boudjella M, Tebaibia A, Touchene B. Esophageal dismotility in scleroderma: a prospective study of 183 cases. Gastronterol Clin Biol 2009;33:466-469.

28. Kimmel JN, Carlson DA, Hinchcliff M, et al. The association between systemic sclerosis disease manifestations and esophageal high-resolution manometry parameters. Neurogastroenterol Motil 2016;28:1157-1165.

29. Crowell MD, Umar SB, Griffing WL, DiBaise JK, Lacy BE, Vela MF. Esophageal motor abnormalities in patients with scleroderma: heterogeneity, risk factors, and effects on quality of life. Clin Gastroenterol Hepatol 2017;15:207-213.

30. Tang DM, Pathikonda M, Harrison M, Fisher RS, Friedenberg FK, Parkman HP. Symptoms and esophageal motility based on phenotypic findings of scleroderma. Dis Esophagus 2013;26:197-203.

31. Bredenoord AJ, Fox M, Kahrilas PJ, Pandolfino JE, Schwizer W, Smout AJ; International High Resolution Manometry Working Group. Chicago classification criteria of esophageal motility disorders defined in high resolution esophageal pressure topography. Neurogastroenterol Motil 2012;24 Suppl 1:57-65.

32. Karamanolis GP, Denaxas K, Panopoulos S, et al. Severe esophageal disease and its associations in systemic sclerosis. Clin Exp Rheumatol 2017;35 Suppl 106:82-85.

33. Arif T, Masood Q, Singh J, Hassan I. Assessment of esophageal involvement in systemic sclerosis and morphea (localized scleroderma) by clinical, endoscopic, manometric and $\mathrm{pH}$ metric features: a prospective comparative hospital based study. BMC Gastroenterol 2015;15:15-24.

34. Weber P, Ganser G, Frosch M, Roth J, Hülskamp G, Zimmer KP. Twenty-four hour intraesophageal $\mathrm{pH}$ monitoring in children and adolescents with scleroderma and mixed connective tissue disease. J Rheumatol 2000;27:2692-2695.

35. Raja J, Ng CT, Sujau I, Chin KF, Sockalingam S. Highresolution oesophageal manometry and 24-hour impedance$\mathrm{pH}$ study in systemic sclerosis patients: association with clinical features, symptoms and severity. Clin Exp Rheumatol 
2016;34 Suppl 100:115-121.

36. Murphy JR, McNally P, Peller P, Shay SS. Prolonged clearance is the primary abnormal reflux parameter in patients with progressive systemic sclerosis and esophagitis. Dig Dis Sci 1992;37:833-841.

37. Fisichella PM, Reder NP, Gagermeier J, Kovacs EJ. Usefulness of $\mathrm{pH}$ monitoring in predicting the survival status of patients with scleroderma awaiting lung transplantation. J Surg Res 2014;189:232-237.

38. Marie I, Ducrotte P, Denis P, Hellot MF, Levesque H. Oesophageal mucosal involvement in patients with systemic sclerosis receiving proton pump inhibitor therapy. Aliment Pharmacol Ther 2006;24:1593-1601.

39. Wipff J, Coriat R, Mascioccchi M, et al. Outcomes of Barrett's esophagus related to systemic sclerosis: a 3-year EULAR Scleroderma Trials and Research prospective follow-up study. Rheumatology 2011;50:1440-1444.

40. Hendel L, Hage E, Hendel J, Stentoft P. Omeprazole in the long-term treatment of severe gastro-oesophageal reflux disease in patients with systemic sclerosis. Aliment Pharmacol Ther 1992;6:565-577.

41. Pakozdi A, Wilson H, Black CM, Denton CP. Does long term therapy with lansoprazole slow progression of oesophageal involvement in systemic sclerosis? Clin Exp Rheumatol 2009;27(3 Suppl 54):5-8.

42. Muro Y, Sugiura K, Nitta Y, et al. Scoring of reflux symptoms associated with scleroderma and the usefulness of rabeprazole. Clin Exper Rheumatol 2009;27(3 Suppl 54):15-21.

43. Hansi N, Thoua N, Carulli M, et al. Consensus best practice pathway of the UK scleroderma study group: gastrointestinal manifestations of systemic sclerosis. Clin Exp Rheumatol 2014;32(6 Suppl 86):S214-S221.

44. Foocharoen C, Chunlerthith K, Mairiang P, et al. Effectiveness of add-on therapy with domperidone vs alginic acid in proton pump inhibitor partial response gastro-esophageal reflux disease in systemic sclerosis: randomized placebo-controlled trial. Rheumatology (Oxford) 2017;56:214-222.

45. Sallam H, McNearney TA, Chen JD. Systematic review: pathophysiology and management of gastrointestinal dysmotility in systemic sclerosis (scleroderma). Aliment Pharmacol Ther 2006;23:691-712.

46. Di Martino N, Ingrosso M, Fei L, Maffettone V, Landolfi V, Del Genio A. [Behavior of the pressure of the lower esophageal sphincter after intravenous administration of domperidone in normal subjects]. Minerva Med 1985;76:1411-1417.
47. Grande L, Lacima G, Ros E, et al. Lack of effect of metoclopramide and domperidone on esophageal peristalsis and esophageal acid clearance in reflux esophagitis. A randomized, double-blind study. Dig Dis Sci 1992;37:583-588.

48. Johnson DA, Drane WE, Curran J, et al. Metoclopramide response in patients with progressive systemic sclerosis. Effect on esophageal and gastric motility abnormalities. Arch Intern Med 1987;147:1597-1601.

49. Ramirez-Mata M, Ibañez G, Alarcon-Segovia D. Stimulatory effect of metoclopramide on the esophagus and lower esophageal sphincter of patients of patients with PSS. Arthritis Rheum 1977;20:30-34.

50. Drane WE, Karvelis K, Johnson DA, Curran JJ, Silverman ED. Scintigraphic detection of metoclopramide esophageal stimulation in progressive systemic sclerosis. J Nucl Med 1987;28:810-815.

51. Wehrmann T, Caspary WF. [Effect of cisapride on esophageal motility in healthy probands and patients with progressive systemic scleroderma]. Klin Wochenschr 1990;68:602-607.

52. Karamanolis GP, Panopoulos S, Karlaftis A, et al. Beneficial effect of the 5-HT1A receptor agonist buspirone on esophageal dysfunction associated with systemic sclerosis: A pilot study. United European Gastroenterol J 2015;3:266-271.

53. Gyger G, Baron M. Systemic sclerosis: gastrointestinal disease and its management. Rheum Dis Clin North Am 2015;41:459-473.

54. Leelakanok N, Holcombe A, Schweizer ML. Domperidone and risk of ventricular arrhythmia and cardiac death: a systematic review and meta-analysis. Clin Drug Investig 2016;36:97-107.

55. Karamanolis GP, Panopoulos S, Denaxas K, et al. The 5-HT1A receptor agonist buspirone improves esophageal motor function and symptoms in systemic sclerosis: a 4-week, open-label trial. Arthritis Res Ther 2016;18:195.

56. Poirier NC, Taillefer R, Topart P, Duranceau A. Antireflux operations in patients with scleroderma. Ann Thoracic Surg 1994;58:66-72.

57. Orringer MB, Orringer JS, Dabich L, Zarafonetis CJ. Combined Collis gastroplasty-fundoplication operations for scleroderma reflux esophagitis. Surgery 1981;90:624-630.

58. Mansour KA, Malone CE. Surgery for scleroderma of the esophagus: a 12-year experience. Ann Thoracic Surg 1988;46:513-514.

59. Kent MS, Luketich JD, Irshad K, et al. Comparison of surgical approaches to recalcitrant gastroesophageal reflux disease in the patient with scleroderma. Ann Thoracic Surg 2007;84:1710-1715. 